\title{
A tribute to Ivan Kiguradze
}

Irena Rachůnkovál* , Svatoslav Staněk , Milan Tvrdý2, Aleksandre Lomtatidze 3 , Ravi P Agarwal ${ }^{4}$, Irina Astashova ${ }^{5}$, Alexander Domoshnitsky ${ }^{6}$, Zuzana Došlá7, Vyacheslav M Evtukhov ${ }^{8}$, Nicolai A Izobov Takasi Kusano ${ }^{10}$, Nino Partsvania ${ }^{11}$, Mykola Perestyuk ${ }^{12}$, Bedřich Půža ${ }^{13}$, Miklós Rontó ${ }^{14}$ and Nicolai Rozov ${ }^{5}$

Dedicated to Professor Ivan Kiguradze for his merits in mathematical sciences.

\author{
*Correspondence: \\ irena.rachunkova@upol.cz \\ 'Department of Mathematics, \\ Faculty of Science, Palacký \\ University, 17. listopadu 12, \\ Olomouc, 77146, Czech Republic \\ Full list of author information is \\ available at the end of the article
}

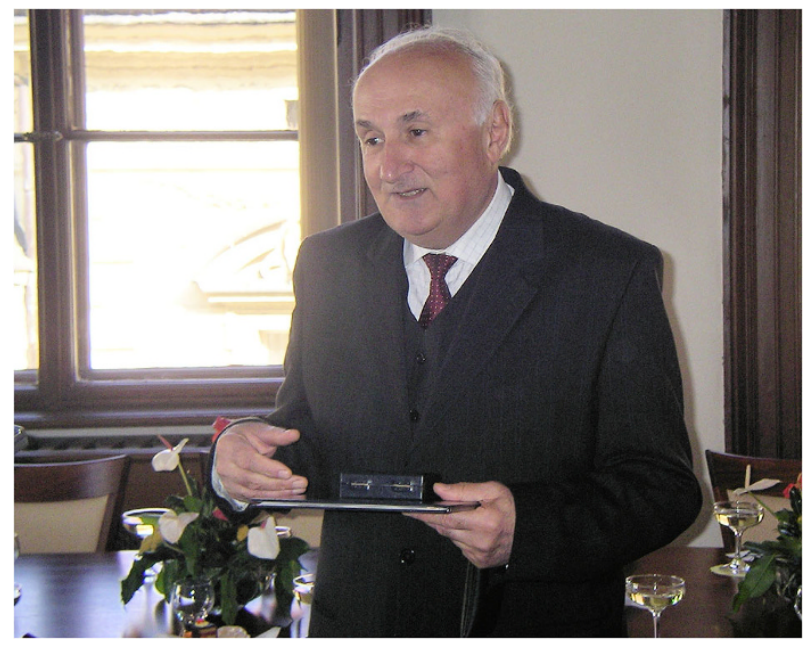

On 12 January 2012, Ivan Kiguradze has celebrated his 75th birthday. A prominent expert in the qualitative theory of differential equations, Professor, Doctor of Science, Academician, he is highly esteemed by his colleagues throughout the world. The ideas and methods due to him are now extensively used. In particular, Kiguradze's lemma, the Kiguradze inequality, Kiguradze classes, and the Kiguradze problem are often encountered in the literature.

Ivan Kiguradze was born in the village of Khidistavi located in the Chokhatauri Municipality in the Guria region of Georgia, where he graduated from the secondary school with a gold medal awarded in 1955.

In 1960, he received his university degree at the Faculty of Mechanics and Mathematics of the Tbilisi State University, where he had been a faculty member then (as an Assistant Professor since 1968 and as a Full Professor since 1973). He entered postgraduate courses at the Chair of Differential and Integral Equations of the Tbilisi State University. In 1963, he obtained a PhD degree, and in 1972 he became Doctor of Science in Physics and Mathematics.

Professor Kiguradze's scientific carrier has always been closely related to the I. Javakhishvili Tbilisi State University and Georgian National Academy of Sciences. Since 1963 till 1989, he had been working at the Tbilisi State University and, since 1973, headed the Department of Ordinary Differential Equations of the Vekua Institute of Applied Mathe-

\section{Springer}

C 2014 Rachůnková et al.; licensee Springer. This is an Open Access article distributed under the terms of the Creative Commons Attribution License (http://creativecommons.org/licenses/by/4.0), which permits unrestricted use, distribution, and reproduction in any medium, provided the original work is properly credited. 
matics. He was elected a Corresponding Member of the Georgian Academy of Sciences (now Georgian National Academy of Sciences) in 1979 and became Academician in 1993. In June 1989, Professor Kiguradze was elected the Director of the A. Razmadze Mathematical Institute of the Georgian Academy of Sciences (now A. Razmadze Mathematical Institute of I. Javakhishvili Tbilisi State University), and he held this position till June 2006. Since 2001 he has been holding a post of a head of the Department of Ordinary Differential Equations at that institute. Since 1973 till 2006, he has also been a Professor of the Chair of Differential and Integral Equations at the I. Javakhishvili Tbilisi State University. Professor Kiguradze has always made many efforts and devoted much energy to pedagogical activities. For more than 40 years he has been teaching general and special courses on ordinary differential equations at the Tbilisi State University, 24 postgraduate students obtained a PhD degree under his supervision. He is actively involved in editorial activities: apart of the membership in the Editorial Boards of several international journals, he is the founder and Editor-in-Chief of Georgian Mathematical Journal and Memoirs on Differential Equations and Mathematical Physics.

Professor Kiguradze's scientific interests cover a wide range of topics belonging to qualitative theory of ordinary and functional-differential equations. They are mainly related to the following three directions: (1) boundary value problems, (2) asymptotic theory, and (3) oscillation theory. Below we try to give a brief survey of his results.

Kiguradze obtained a number of a priori estimates for one-sided differential inequalities subject some boundary value conditions; these estimates form a basis for the construction of a complete theory of initial and boundary value problems for differential equations and systems with nonintegrable singularities with respect to the time variable. In particular, he established sharp criteria providing the solvability and unique solvability of:

- the Cauchy problem [9-11, 79];

- the Cauchy-Nicoletti problem [20, 41];

- the modified Cauchy-Nicoletti problem [42];

- the Vallée-Poussin problem [24, 57, 60, 61];

- the periodic problem [32];

- various two-point problems (together with BL Shekhter) [13, 17, 21, 23, 26-28, 33, 38, 51, 52, 66, 72, 115, 116, 136];

- multipoint and nonlocal problems (together with RP Agarwal, T Kiguradze, A Lomtatidze, and N Partsvania) [54, 66, 119, 141, 142, 146, 147].

Kiguradze together with RP Agarwal developed a new method for investigation of boundary value problems for differential equations with strong singularities with respect to the time variable, on the basis of which he obtained unimprovable conditions for the solvability of the Dirichlet and focal boundary value problems for higher-order strongly singular linear, quasi-half linear, and nonlinear differential equations [120, 125, 145].

For nonlinear differential equations with singularities with respect to phase variables, Kiguradze established optimal sufficient conditions for the solvability of the Cauchy problem [148], nonlocal problems [149, 150] and periodic type problems [151].

Kiguradze established inequalities of the Kolmogorov-Gorni type for monotone functions, on the basis of which sharp conditions for the solvability of the Kneser problem for nonlinear differential equations were found and asymptotic estimates for Kneser solutions were proved [16, 19, 22, 47]. Together with I Rachůnková he obtained complete results on the solvability of the Kneser problem for two-dimensional differential systems [48]. More- 
over, he obtained necessary and sufficient conditions for the existence of Kneser solutions blowing-up and vanishing at infinity for higher-order nonlinear differential equations with singularities with respect to the time and phase variables, as well as global two-sided estimates for such solutions $[105,107]$.

On the basis of the technique of a priori estimates and generalization of the notion of lower and upper Nagumo functions for differential systems, Kiguradze and his students completely studied a wide class of problems with nonlinear and nonlocal boundary conditions [ $30,31,37,39,43,44,55,56,58,65,67,118,126,140,144]$. In particular, he proved the solvability of these problems for nonlinear differential equations and systems with right-hand sides rapidly increasing with respect to the phase variable, introduced the notion of a strong isolated solution of a nonlinear problem, proved the stability of such a solution under small perturbations of the differential system. Together with $\mathrm{T}$ Kiguradze he also obtained unimprovable sufficient conditions for solvability and unique solvability of nonlocal boundary value problems for higher-order nonlinear partial differential equations of hyperbolic type [130].

Kiguradze proved the general theorem on the solvability of a nonlinear operator equation in the Banach space (so-called principle of a priori boundedness), on the basis of which he established abstract analogs of the well-known Conti-Opial type theorems in the theory of differential equations [132].

A fundamental contribution was made by Kiguradze to the theory of boundary value problems on an infinite interval. In particular:

- for nonautonomous differential systems, he found unimprovable conditions which guarantee, respectively, the existence, uniqueness and stability of periodic, bounded and vanishing at infinity solutions $[45,63,65,80,117,121,137,138]$;

- for second-order nonlinear nonautonomous differential equations, he proved theorems on the existence of at least one periodic solution $[18,40]$ and an infinite set of periodic solutions [135], and together with S Staněk he established sufficient conditions for the existence of extremal solutions of a periodic problem [110];

- together with T Kusano, A Lomtatidze and S Baslandze he established unimprovable sufficient conditions for the existence and uniqueness of periodic solutions of higher-order nonlinear nonautonomous differential equations [59, 99, 102, 106, 108, 124, 131, 139].

Attempts to find criteria for the existence of so-called proper solutions of strongly nonlinear differential equations led Kiguradze to boundary value problems on a semiaxis with integral conditions, whose theory was developed in [51, 64, 75].

Some of the above-mentioned results, dealing with boundary value problems, were summarized in the monographs $[40,81,82]$ and the surveys $[65,66]$, well known to specialists and often used by them.

Kiguradze has studied in detail boundary value problems for functional-differential equations, as well. In particular, together with B Půža he proved:

- criteria for the Fredholm property and well-posedness of boundary value problems with functional conditions for both regular $[84,114]$ and singular $[109,115]$ linear differential and functional-differential systems;

- description of a class of linear boundary value problems for which the entries of Green's matrix are sign-constant $[81,82,104,114]$; 
- efficient and sharp conditions ensuring the unique solvability of multipoint and periodic type problems for regular linear differential systems and equations [81-84, 86, 117, 124] and two-point boundary value problems for singular differential systems [83, 115];

- optimal, in a sense, conditions for the Fredholm property and unique solvability of two-point boundary value problems for higher-order linear differential equations with strong singularities, as well as conditions for the stability of the solutions under small perturbations of the right-hand side of the equation [119, 125].

Together with S Gelashvili he found sufficient conditions for the unique solvability of multipoint boundary value problems for systems of functional-differential equations, and constructed stable finite-difference schemes for the numerical solution of such problems [78].

Having improved the technique of a priori estimates for solutions of one-sided differential inequalities with nonlinear boundary conditions, Prof. Kiguradze together with R Hakl, N Partsvania, B Půža, Z Sokhadze, and IP Stavroulakis developed a new method for the investigation of nonlinear boundary value problems, which was then efficiently used to obtain the following results:

- general theorems on the solvability of nonlinear boundary value problems for systems of regular $[88,92]$ and singular $[109,113]$ functional-differential equations (the principle of $a$ priori boundedness and the Conti-Opial type theorems);

- optimal conditions for the local and global solvability and the unique solvability of the weighted Cauchy problem $[77,87,89,90]$ for systems of nonlinear evolution singular functional-differential equations; in the cases where there is no uniqueness, the structure of the solution set of the problem is analyzed [95];

- Kamke type theorems on the existence of minimal and maximal solutions of a multipoint and periodic boundary value problems for regular nonlinear differential systems [91, 104] , as well as solvability and well-posedness criteria [91-93, 98, 103, 123, 133];

- sufficient conditions for the solvability of the Kneser and two-point boundary value problems for higher-order nonlinear functional-differential equations and for two-dimensional nonlinear functional-differential systems with advanced arguments $[69,101,111]$;

- criteria for the solvability and unique solvability of the Vallée-Poussin and Dirichlet problems for singular functional-differential equations [85, 109, 122];

- an analog of the Fredholm theorem for the so-called semilinear boundary value problems, which implies, in particular, sharp integral solvability conditions of a two-point boundary value problem for semilinear second-order singular differential equations [109].

From the 1960s to the beginning of the 1990s Kiguradze and his students ( $T$ Chanturia, G Kvinikadze, D Izjumova) studied the asymptotic behavior of solutions of nonautonomous ordinary differential equations including equations with power nonlinearities of the Emden-Fowler type.

Kiguradze constructed a transformation that reduces a second-order Emden-Fowler equation to an equation with almost constant coefficients and developed a technique for the study of the latter. This method allowed him to derive asymptotic formulas for an ar- 
bitrary proper solution of the general Emden-Fowler equation both in the oscillation and nonoscillation cases $[3,6,12]$.

For second- and higher-order strongly nonlinear differential equations, Kiguradze proved the existence of singular solutions of the first and the second kind and proper solutions of various types (bounded, vanishing at infinity, slowly increasing, rapidly increasing, etc.) and established asymptotic estimates for such solutions $[4,7,15,49-51$, 68]. For linear equations, he established asymptotic representations of solutions $[5,68]$ and solved the Bernatskii problem on the dimension of the space of solutions vanishing at infinity [53].

For the Emden-Fowler type two-dimensional differential system, Kiguradze together with M Cecchi, Z Došlá, and M Marini obtained optimal conditions guaranteeing the existence of positive solutions of two-point boundary value problems. On the basis of this result they proved the theorem on the existence of blow-up solutions of the abovementioned system and obtained asymptotic estimates of these solutions [129].

Kiguradze's studies played a distinguished role in the development of the theory of oscillations of differential and functional-differential equations. He developed in some sense final criteria for the oscillation of solutions to linear differential equations and differential equations of the Emden-Fowler type [1, 2, 4, 14, 34]. For nonlinear equations of higher order, Kiguradze suggested the construction of a first-order equation the absence of whose proper solutions results in oscillation property of the original equation. The sufficient criteria of the oscillation property thus obtained are necessary for a wide class on nonlinear differential equations $[1,4,8,25,35,36,46,62,68,70]$.

We must especially point out Kiguradze's theorems related to the existence of proper oscillatory solutions of essentially nonlinear differential equations [51, 68]. These are the results that bring the theory of oscillations into a complete form.

The most of the results by Kiguradze and his disciples on the asymptotic and oscillation of solutions of nonautonomous differential equations were summarized in his monograph [68] written jointly with T Chanturia and translated into English [71].

Deep and complete results are obtained by Kiguradze in the qualitative theory of functional-differential equations as well. In particular:

- together with Z Došlá he established criteria for boundedness, stability and vanishing at infinity of solutions of second-order linear advanced differential equations [96, 100];

- together with D Chichua he proved the theorem on the existence of proper oscillatory solutions for higher-order essentially nonlinear functional-differential equations [76];

- together with N Partsvania and IP Stavroulakis he found necessary and sufficient conditions for the oscillation of solutions of nonlinear advanced functional-differential equations [94, 97, 112];

- together with N Partsvania he proved the Esclangon-Landau type theorem on a priori estimates of bounded solutions of systems of higher-order nonlinear functional-differential equations [127];

- together with Z Sokhadze he established a priori estimates of solutions of systems of functional-differential inequalities appearing in the theory of boundary value problems, as well as in the stability theory. On the basis of these estimates, they obtained new sufficient conditions for the boundedness, uniform stability, and uniform asymptotic stability of solutions of nonlinear delay differential systems [128]. 
On behalf of many his friends and colleagues all over the world, let us wish Professor Ivan Kiguradze good health, a long life, and new inspiration and creative success.
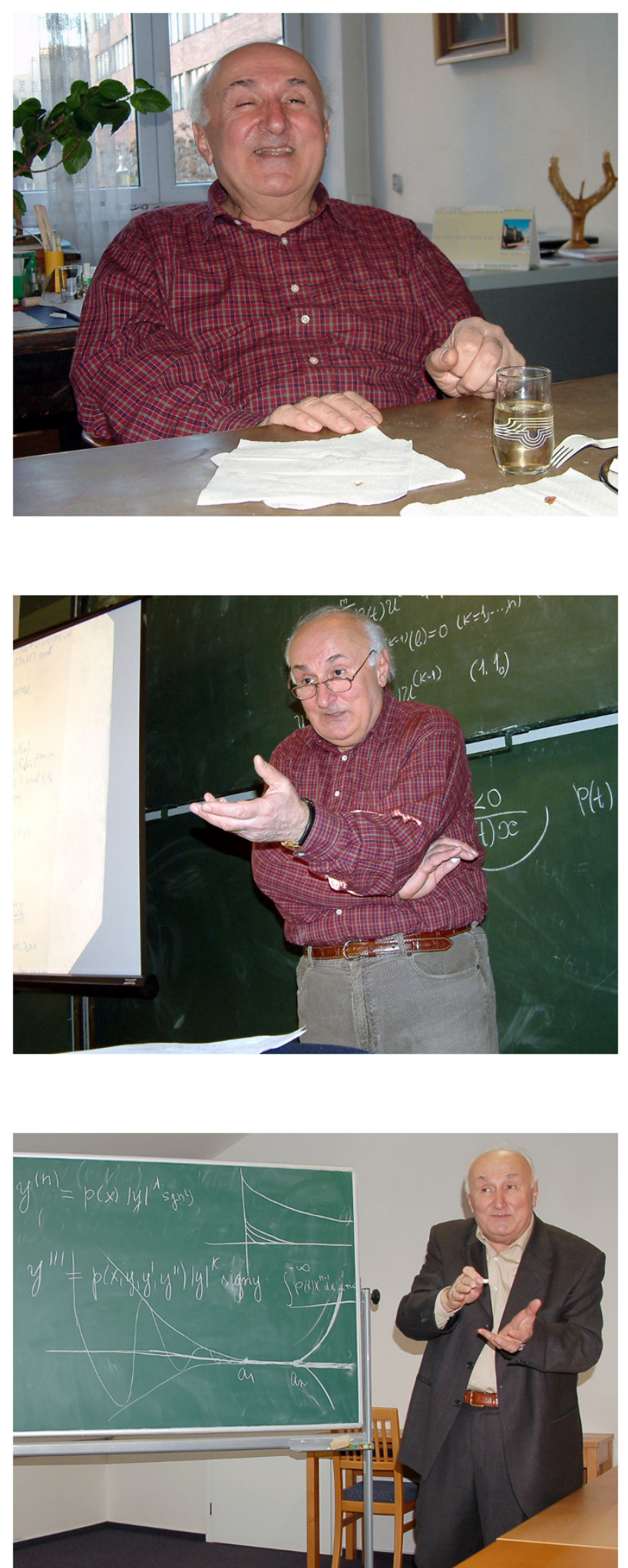

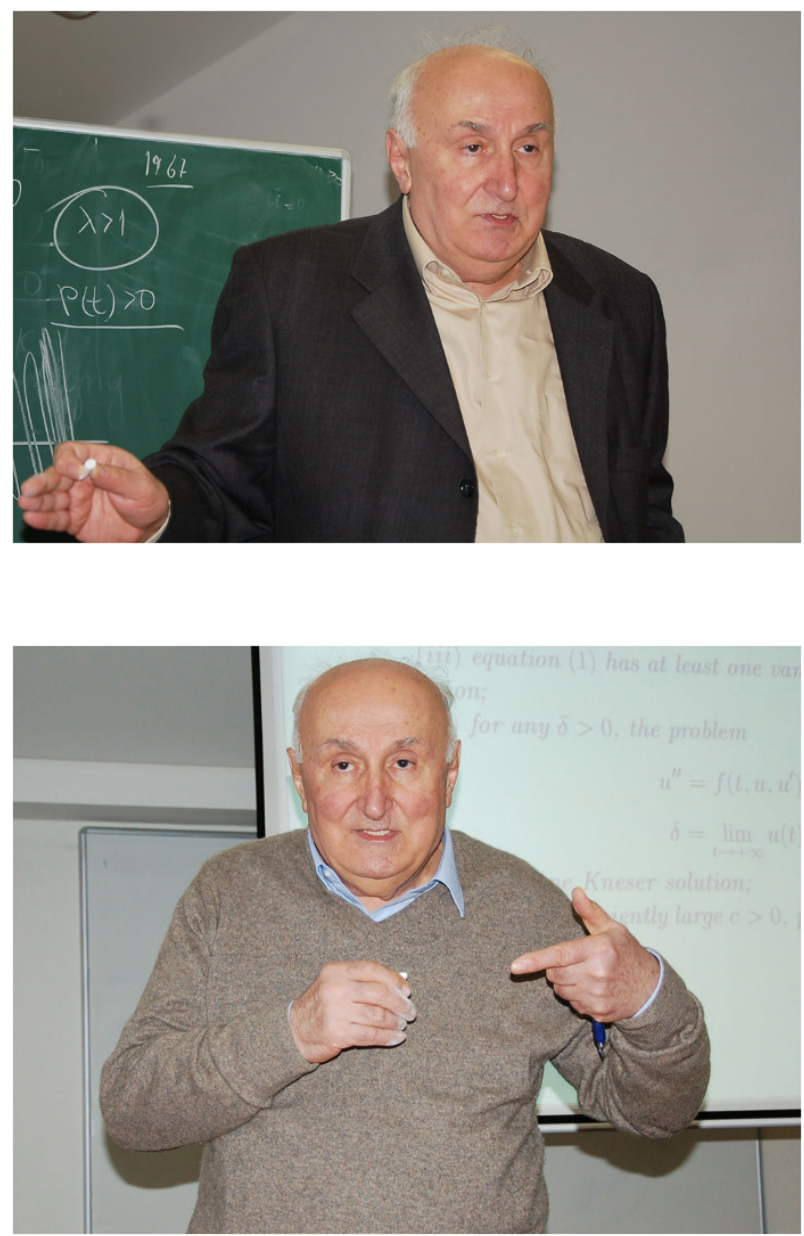

\section{Competing interests}

The authors declare that they have no competing interests.

\section{Authors' contributions}

All authors read and approved the final manuscript.

\section{Author details}

${ }^{1}$ Department of Mathematics, Faculty of Science, Palacký University, 17. listopadu 12, Olomouc, 77146, Czech Republic. ${ }^{2}$ Institute of Mathematics, Academy of Sciences of the Czech Republic, Žitná 25, Praha, 11567, Czech Republic. ${ }^{3}$ Institute of Mathematics, Academy of Sciences of the Czech Republic, Branch in Brno, Žižkova 22, Brno, 61262, Czech Republic. ${ }^{4}$ Department of Mathematics, Texas A\&M University-Kingsville, 700 University Blvd., Kingsville, TX 78363-8202, USA. ${ }^{5}$ Faculty of Mechanics and Mathematics, Lomonosov Moscow State University, Moscow, Russia. ${ }^{6}$ Department of Mathematics and Computer Sciences, Ariel University, Ariel, 44837, Israel. ${ }^{7}$ Department of Mathematics and Statistics, Faculty of Sciences, Masaryk University, Kotlárská 2, Brno, 61137, Czech Republic. ${ }^{8}$ The Institute of Mathematics, Economics and Mechanics, Odessa I.I. Mechnikov National University, Dvoryanska 2, Odessa, 65082, Ukraine. ${ }^{9}$ State Scientific Institution, The Institute of Mathematics, 11 Surganov Street, Minsk, 220072, Belarus. ${ }^{10}$ Department of Mathematics, Faculty of Science, Hiroshima University, Higashi-Hiroshima, 739-8526, Japan. ${ }^{11}$ Andrea Razmadze Mathematical Institute, I. Javakhishvili Tbilisi State University, 6, Tamarashvili Str., Tbilisi, 0177, Georgia. ${ }^{12}$ Faculty of Mechanics and Mathematics, Taras Shevchenko National University of Kiev, Academician Glushkov Prospectus, Kyiv, 03127, Ukraine. ${ }^{13}$ Institute of Informatics, Faculty of Business and Management, Technical University in Brno, Kolejní 2906/4, Brno, 61200, Czech Republic. ${ }^{14}$ Department of Analysis, Faculty of Mechanical Engineering and Information Science, University of Miskolc, Miskolc-Egyetemváros, Miskolc, 3515, Hungary.

\section{Received: 1 October 2014 Accepted: 1 October 2014 Published online: 15 October 2014}

\section{List of the main publications by Ivan Kiguradze}

1. On the oscillation of solutions of some ordinary differential equations. Sov. Math. Dokl. 3, 649-652 (1962)

2. On oscillation conditions for solutions of the equation $u^{\prime \prime}+a(t)|u|^{n} \operatorname{sign} u=0$. Čas. Pěst. Mat. 87(4), 492-495 (1962) (in Russian)

3. On asymptotic properties of solutions of the equation $u^{\prime \prime}+a(t)|u|^{n} \operatorname{sign} u=0$. Soobshch. Akad. Nauk Gruz. SSR 30(2), 129-136 (1963) (in Russian) 
4. On the oscillation of solutions of the equation $\mathrm{d}^{m} u / \mathrm{d} t^{m}+a(t)|u|^{n} \operatorname{sign} u=0$. Mat. Sb. 65(2), 172-187 (1964) (in Russian)

5. On the asymptotic representation of solutions of linear differential equations. Tr. Tbilis. Univ. Mat. Mekh. Astron. 102, 149-167 (1964) (in Russian)

6. On nonoscillatory solutions of the equation $u^{\prime \prime}+a(t)|u|^{n} \operatorname{sign} u=0$. Soobshch. Akad. Nauk Gruz. SSR 35(1), 15-22 (1964) (in Russian)

7. A note on the boundedness of solutions of differential equations. Tr. Tbilis. Univ. Mat. Mekh. Astron. 110, 103-108 (1965) (in Russian)

8. Concerning the oscillation of solutions of nonlinear differential equations. Differ. Uravn. 1(8), 995-1006 (1965) (in Russian)

9. Comparison lemma and the question of uniqueness of solutions of the Cauchy problem for ordinary differential equations. Soobshch. Akad. Nauk Gruz. SSR 39(3), 513-518 (1965) (in Russian)

10. On the Cauchy problem for ordinary differential equations with singularity. Soobshch. Akad. Nauk Gruz. SSR 37(1), 19-24 (1965) (in Russian)

11. On the Cauchy problem for singular systems of ordinary differential equations. Differ. Uravn. 1(10), 1271-1291 (1965) (in Russian)

12. Asymptotic properties of solutions of a nonlinear differential equation of Emden-Fowler type. Izv. Akad. Nauk SSSR, Ser. Mat. 29(5), 965-986 (1965) (in Russian)

13. On a priori estimates of derivatives of bounded functions satisfying second order differential inequalities. Differ. Uravn. 3(7), 1043-1052 (1967) (in Russian)

14. A note on the oscillation of solutions of the equation $u^{\prime \prime}+a(t)|u|^{n} \operatorname{sign} u=0$. Čas. Pěst. Mat. 92(3), 343-350 (1967) (in Russian)

15. Some remarks on the solutions of the equation $u^{\prime \prime}+a(t) f(u)=0$. Differ. Uravn. 4(4), 589-605 (1968) (in Russian) (together with Izjumova, DV)

16. On the monotone solutions of nonlinear $n$-th order ordinary differential equations. Dokl. Akad. Nauk SSSR 181(5), 1054-1057 (1968) (in Russian)

17. On some singular boundary value problems for nonlinear second order ordinary differential equations. Differ. Uravn. 4(10), 1753-1773 (1968) (in Russian)

18. On periodic solutions of nonlinear second order differential equations. In: Proc. of IV Conf. on Nonlinear Oscillations, pp. 175-180. Academia, Prague (1968)

19. On non-negative non-increasing solutions of non-linear second order differential equations. Ann. Mat. Pura Appl. 81, 169-192 (1969)

20. On the singular problem of Nicoletti. Dokl. Akad. Nauk SSSR 86(4), 769-772 (1969) (in Russian)

21. On nonoscillation conditions for singular linear second order differential equations. Mat. Zametki 6(5), 633-639 (1969) (in Russian)

22. On monotone solutions of nonlinear $n$-th order ordinary differential equations. Izv. Akad. Nauk SSSR, Ser. Mat. 33(6), 1373-1398 (1969) (in Russian)

23. On a singular two-point boundary value problem. Differ. Uravn. 5(11), 2002-2016 (1969) (in Russian)

24. On a singular multi-point boundary value problem. Ann. Mat. Pura Appl. 86, 367-399 (1970)

25. On oscillatory solutions of nonlinear ordinary differential equations. In: Proc. of 5 th Intern. Conf. on Nonlinear Oscillations, Kiev, vol. 1, pp. 293-298 (1970) (in Russian)

26. On a singular boundary value problem. J. Math. Anal. Appl. 30(3), 475-489 (1970)

27. On the existence and uniqueness of solutions of singular boundary value problem. Fasc. Math. 5(74), 5-16 (1970)

28. On a singular boundary value problem for the $n$-th order ordinary differential equation. Dokl. Akad. Nauk SSSR 192(5), 973-975 (1970) (in Russian)

29. Remarks on the asymptotic behaviour of solutions of the equation $u^{\prime \prime}+a(t) u=0$. Differ. Uravn. 6(6), 115-117 (1970) (in Russian) (together with Chanturia, TA)

30. On a boundary value problem for a system of two differential equations. Proc. Tbil. Univ. 1(137)A, 77-87 (1971) (in Russian)

31. On a boundary value problem for the system of ordinary differential equations. Differ. Uravn. 7(9), 1611-1616 (1971) (in Russian) (together with Kakabadze, MA)

32. On periodic solutions of the system of ordinary differential equations with singularities. Dokl. Akad. Nauk SSSR 198(2), 286-289 (1971) (in Russian)

33. On a singular boundary value problem for an $n$-th order ordinary differential equation. Tr. Inst. Prikl. Mat. Tbilis. Univ. 3, 187-206 (1972) (in Russian)

34. Oscillatory solutions for a generalized sublinear second order differential equation. Proc. Am. Math. Soc. 38(1), 80-82 (1973) (together with Heidel, JW)

35. On oscillation conditions for solutions of nonlinear ordinary differential equations, I. Differ. Uravn. 10(8), 1387-1399 (1974) (in Russian)

36. On oscillation conditions for solutions of nonlinear ordinary differential equations, II. Differ. Uravn. 10(9), 1586-1594 (1974) (in Russian)

37. Concerning the solvability of nonlinear two-point boundary value problems. Mat. Zametki 16(3), $479-490$ (1974) (in Russian) (together with Lezhava, NR)

38. Concerning nonoscillatory singular linear second order differential equations. Differ. Uravn. 10(11), 2064-2067 (1974) (in Russian) (together with Gogiberidze, NV)

39. On some nonlinear two-point boundary value problems. Differ. Uravn. 10(12), 2147-2161 (1974) (in Russian) (together with Lezhava, NR)

40. Some singular boundary value problems for ordinary differential equations, Tbilisi (1975) (in Russian)

41. On a singular problem of Cauchy-Nicoletti. Ann. Mat. Pura Appl. 104, 151-175 (1975)

42. On the modified problem of Cauchy-Nicoletti. Ann. Mat. Pura Appl. 104, 177-186 (1975)

43. On some boundary value problems for a system of ordinary differential equations. Differ. Uravn. 12(12), 2139-2148 (1976) (in Russian) (together with Půža, B) 
44. On a nonlinear boundary-value problem. In: Function Theoretic Methods in Diff. Equations, pp. 259-276. Pitman, London (1976) (together with Lezhava, NR)

45. On the periodic boundary value problem for the two-dimensional differential system. Differ. Uravn. 13(6), 996-1007 (1977) (in Russian)

46. On oscillatory and monotone solutions of ordinary differential equations. Arch. Math. 14(1), $21-44$ (1978)

47. On the solvability of a nonlinear Kneser type problem. Differ. Uravn. 15(10), 1754-1765 (1979) (in Russian) (together with Rachůnková, I)

48. On a certain nonlinear problem for two-dimensional differential systems. Arch. Math. 16(1), 15-38 (1980) (together with Rachůnková, I)

49. On asymptotic behaviour of solutions of nonlinear non-autonomous ordinary differential equations. In: Qual. Theory Differ. Equ., vol. 1, pp. 507-554. Amsterdam e.a. (1981)

50. On strongly increasing solutions of nonlinear ordinary differential equations. Ann. Mat. Pura Appl. 130, 67-87 (1982) (together with Kvinikadze, GG)

51. On some singular boundary-value problems for ordinary differential equations. In: Equadiff 5, Proc. 5 Czech. Conf. Differ. Equations and Appl., pp. 174-178. Teubner, Leipzig (1982)

52. On numerical solution of two-point boundary value problems for second order ordinary differential equations. $\mathrm{Tr}$. Inst. Prikl. Mat. Im. I. N. Vekua 14, 69-127 (1983) (together with Tabidze, GS)

53. On vanishing at infinity solutions of ordinary differential equations. Czechoslov. Math. J. 33(4), $613-646$ (1983)

54. On certain boundary-value problems for second-order linear ordinary differential equations with singularities. J. Math. Anal. Appl. 101(2), 325-347 (1984) (together with Lomtatidze, AG)

55. On two-point boundary value problems for systems of nonlinear ordinary differential equations. In: IX Intern. Conf. on Nonlinear Oscillations, vol. 1, pp. 168-173. Naukova Dumka, Kiev (1984) (in Russian)

56. On the stability of the set of solutions of nonlinear boundary value problems. Differ. Uravn. 20(9), 1495-1501 (1984) (in Russian) (together with Bitsadze, DG)

57. On the behaviour of solutions of higher order ordinary differential equations in the neighbourhood of a singular point. Differ. Uravn. 20(10), 1703-1709 (1984) (in Russian)

58. On a multi-point boundary value problem for systems of ordinary differential equations. Tr. Tbilis. Univ. 259, 110-121 (1984) (in Russian)

59. On bounded and periodic solutions of linear higher order differential equations. Mat. Zametki 37(1), 48-62 (1985) (in Russian)

60. On a priori estimates of solutions of nonlinear higher order differential inequalities. Differ. Uravn. 21(2), 198-213 (1985) (in Russian)

61. On the solvability of the Vallée-Poussin problem. Differ. Uravn. 21(3), 391-398 (1985) (in Russian)

62. On oscillatory properties of a class of differential equations with deviating argument. Differ. Uravn. 21(4), 588-596 (1985) (in Russian) (together with Izjumova, DV)

63. On periodic solutions of systems of nonautonomous ordinary differential equations. Mat. Zametki 39(4), 562-575 (1986) (in Russian)

64. On a boundary value problem with a condition at infinity for higher order ordinary differential equations. In: Trudy Vsesojuznogo Simpoziuma po Diff. Uravnenijam v Chastnykh Proizvodnykh, pp. 91-105. Tbilis. Univ. Press, Tbilisi (1986) (in Russian)

65. Boundary value problems for systems of ordinary differential equations. J. Sov. Math. 43(2), 2259-2339 (1988)

66. Singular boundary value problems for second-order ordinary differential equations. J. Sov. Math. 43(2), 2340-2417 (1988) (together with Shekhter, BL)

67. On some boundary value problems for systems of nonlinear ordinary differential equations. In: Equadiff 7 , Proceedings of the Conference held in Prague, 1989, pp. 37-46. Teubner, Leipzig (1990)

68. Asymptotic properties of solutions of nonautonomous ordinary differential equations. Nauka, Moscow (1990) (in Russian) (together with Chanturiya, TA)

69. On the Kneser problem for functional differential equations. Differ. Uravn. 27(11), 1879-1892 (1991) (in Russian) (together with Chichua, DI)

70. An oscillation criterion for a class of ordinary differential equations. Differ. Uravn. 28(2), 207-219 (1992) (in Russian)

71. Asymptotic properties of solutions of nonautonomous ordinary differential equations. Kluwer Academic, Dordrecht (1992) (together with Chanturiya, TA)

72. On the two-point boundary value problems for systems of higher order ordinary differential equations with singularities. Georgian Math. J. 1(1), 31-45 (1994) (together with Tskhovrebadze, G)

73. On some properties of solutions of second order linear functional differential equations. Georgian Math. J. 1(5), 487-494 (1994)

74. On asymptotic properties of solutions of third order linear differential equations with deviating arguments. Arch. Math. 30(1), 59-72 (1994)

75. On some boundary value problems with integral conditions for functional differential equations. Georgian Math. J. 2(2), 165-188 (1995) (together with Chichua, D)

76. On proper oscillatory and vanishing at infinity solutions of differential equations with a deviating argument. Georgian Math. J. 2(4), 395-418 (1995) (together with Chichua, D)

77. Concerning the uniqueness of solution of the Cauchy problem for functional differential equations. Differ. Uravn. 31(12), 1977-1988 (1995) (in Russian) (together with Sokhadze, Z)

78. On multi-point boundary value problems for systems of functional differential and difference equations. Mem. Differ. Equ. Math. Phys. 5, 1-113 (1995) (together with Gelashvili, S)

79. On the singular Cauchy problem for systems of linear ordinary differential equations. Differ. Uravn. 32(2), 215-223 (1996) (in Russian)

80. On the correctness of Cauchy problem for the linear differential system on an infinite interval. Georgian Math. J. 3(5), 475-484 (1996)

81. Initial and boundary value problems for systems of ordinary differential equations, I, Tbilisi (1997) (in Russian)

82. Boundary value problems for systems of linear ordinary differential equations, Brno (1997) (in Czech) 
83. On a certain singular boundary value problem for linear differential equations with deviating arguments. Czechoslov. Math. J. 47(2), 233-244 (1997) (together with Půža, B)

84. On boundary value problems for systems of linear functional differential equations. Czechoslov. Math. J. 47(2), 341-373 (1997) (together with Půža, B)

85. On the Vallée-Poussin problem for singular differential equations with deviating arguments. Arch. Math. 33(12), 127-138 (1997) (together with Půža, B)

86. On periodic solutions of systems of linear functional differential equations. Arch. Math. 33(3), 197-212 (1997) (together with Půža, B)

87. On the Cauchy problem for evolution singular functional-differential equations. Differ. Uravn. 33(1), 48-59 (1997) (in Russian) (together with Sokhadze, ZP)

88. Conti-Opial type theorems for nonlinear functional-differential equations. Differ. Uravn. 33(2), 185-194 (1997) (in Russian) (together with Půža, B)

89. On singular functional differential inequalities. Georgian Math. J. 4(3), 259-278 (1997) (together with Sokhadze, Z)

90. On the global solvability of the Cauchy problem for singular functional differential equations. Georgian Math. J. 4(4), 355-372 (1997) (together with Sokhadze, Z)

91. On systems of ordinary differential equations and differential inequalities with multi-point boundary conditions. Differ. Uravn. 33(5), 646-652 (1997)

92. On boundary value problems for functional differential equations. Mem. Differ. Equ. Math. Phys. 12, 106-113 (1997) (together with Pưža, B)

93. On the solvability of nonlinear boundary value problems for functional differential equations. Georgian Math. J. 5(3), 251-262 (1998) (together with Pưža, B)

94. On existence of proper oscillating solutions of differential equations with advanced arguments. Differ. Uravn. 34(6), 751-757 (1998) (together with Stavroulakis, IP)

95. On the structure of the set of solutions of the weighted Cauchy problem for evolution singular functional differential equations. Fasc. Math. 28, 71-92 (1998) (together with Sokhadze, Z)

96. On vanishing at infinity solutions of second order linear differential equations with advanced arguments. Funkc. Ekvacioj 41(2), 189-205 (1998) (together with Došlá, Z)

97. On the oscillation of solutions of higher order Emden-Fowler advanced differential equations. Appl. Anal. 70(12), 97-112 (1998) (together with Stavroulakis, IP)

98. On periodic solutions of nonlinear functional differential equations. Georgian Math. J. 6(1), 47-66 (1999) (together with Půža, B)

99. On periodic solutions of nonautonomous ordinary differential equations of higher order. Differ. Uravn. 35(1), 72-78 (1999) (together with Kusano, T)

100. On boundedness and stability of solutions of second order linear differential equations with advanced arguments. Adv. Math. Sci. Appl. 9(1), 1-24 (1999) (together with Došlá, Z)

101. On nonnegative solutions of nonlinear two-point boundary value problems for two-dimensional differential systems with advanced arguments. Electron. J. Qual. Theory Differ. Equ. 1999, 5 (1999) (together with Partsvania, N)

102. On periodic solutions of $n$-th order ordinary differential equations. Nonlinear Anal. 40(18), 309-321 (2000)

103. On periodic solutions of systems of differential equations with deviating arguments. Nonlinear Anal. 42(2), 229-242 (2000) (together with Půža, B)

104. Upper and lower solutions of boundary value problems for functional differential equations and theorems on functional differential inequalities. Georgian Math. J. 7(3), 489-512 (2000) (together with Hakl, R, Půža, B)

105. On Kneser solutions of the Emden-Fowler differential equation with a negative exponent. Tr. Inst. Mat. NAN Belarusi 4, 69-77 (2000)

106. On existence and uniqueness conditions for periodic solutions of nonautonomous differential equations. Differ. Uravn. 36(10), 1301-1306 (2000) (together with Kusano, T)

107. On blow-up Kneser solutions of higher-order nonlinear differential equations. Differ. Uravn. 37(6), 735-743 (2001)

108. On periodic solutions of even-order ordinary differential equations. Ann. Mat. Pura Appl. 180(3), 285-301 (2001) (together with Kusano, T)

109. On singular boundary value problems for functional differential equations of higher order. Georgian Math. J. 8(4), 791-814 (2001) (together with Půža, B, Stavroulakis, IP)

110. On periodic boundary value problem for the equation $u^{\prime \prime}=f\left(t, u, u^{\prime}\right)$ with one-sided growth restrictions on $f$. Nonlinear Anal. 48(7), 1065-1075 (2002) (together with Staněk, S)

111. On the Kneser problem for two-dimensional differential systems with advanced arguments. J. Inequal. Appl. 7(4), 453-477 (2002) (together with Partsvania, N)

112. On oscillation properties of higher-order functional-differential equations with advanced arguments. Differ. Uravn. 38(8), 1030-1041 (2002) (together with Partsvaniya, NL, Stavroulakis, IP)

113. Conti-Opial type existence and uniqueness theorems for nonlinear singular boundary value problems. Funct. Differ Equ. 9(3-4), 405-422 (2002) (together with Půža, B)

114. Boundary value problems for systems of linear functional differential equations. Folia Facul. Sci. Natur. Univ. Masar. Brun., Mathematica, vol. 12. Masaryk University, Brno (2003) (together with Půža, B)

115. On boundary value problems for linear differential systems with singularities. Differ. Uravn. 39(2), 198-209 (2003) (in Russian)

116. Some optimal conditions for the solvability of two-point singular boundary value problems. Funct. Differ. Equ. 10(12), 259-281 (2003)

117. On periodic type solutions of systems of linear ordinary differential equations. Abstr. Appl. Anal. 5, 395-406 (2004)

118. On nonlinear boundary value problems for two-dimensional differential systems. Differ. Uravn. 40(6), 747-755 (2004) (in Russian) (together with Mukhigulashvili, SV)

119. On multi-point boundary value problems for linear ordinary differential equations with singularities. J. Math. Anal. Appl. 297, 131-151 (2004) (together with Agarwal, RP)

120. On two-point boundary value problems for higher order singular ordinary differential equations. Mem. Differ. Equ. Math. Phys. 31, 101-107 (2004) 
121. On periodic solutions of two-dimensional nonautonomous differential systems. Nonlinear Anal. 60(2), 241-256 (2005) (together with Mukhigulashvili, S)

122. On two-point boundary value problems for second order singular functional differential equations. Funct. Differ. Equ. 12(3-4), 271-294 (2005) (together with Půža, B)

123. On some boundary value problems for fourth order functional differential equations. Mem. Differ. Equ. Math. Phys. 35, 55-64 (2005) (together with Půža, B)

124. On the unique solvability of a periodic boundary value problem for third-order linear differential equations. Differ. Uravn. 42(2), 153-158 (2006) (together with Baslandze, SR)

125. Two-point boundary value problems for higher-order linear differential equations with strong singularities. Bound. Value Probl. 2006, Article ID 83910 (2006) (together with Agarwal, RP)

126. On nonlinear boundary value problems for higher order ordinary differential equations. In: Proceedings of the Conference on Differential and Difference Equations and Applications, pp. 529-540. Hindawi Publ. Corp., New York (2006)

127. On a priori estimates of solutions of systems of higher order nonlinear functional differential inequalities. Georgian Math. J. 14(3), 445-456 (2007) (together with Partsvania, N)

128. A priori estimates of solutions of systems of functional differential inequalities, and some of their applications. Mem Differ. Equ. Math. Phys. 41, 43-67 (2007) (together with Sokhadze, Z)

129. On nonnegative solutions of singular boundary value problems for Emden-Fowler-type differential systems. Differ. Integral Equ. 20(10), 1081-1106 (2007) (together with Cecchi, M, Došlá, Z, Marini, M)

130. On solvability of boundary value problems for higher order nonlinear hyperbolic equations. Nonlinear Anal. 69 , 1914-1933 (2008) (together with Kiguradze, T)

131. On a resonance periodic problem for non-autonomous high order differential equations. Differ. Uravn. 44(8), 1022-1032 (2008) (in Russian)

132. On solvability conditions for nonlinear operator equations. Math. Comput. Model. 48(11-12), 1914-1924 (2008)

133. On periodic solutions of higher order functional differential equations. Bound. Value Probl. 2008, Article ID 389028 (2008) (together with Partsvania, N, Půža, B)

134. Beurling-Borg type theorem for two-dimensional linear differential systems. Georgian Math. J. 15(4), 677-682 (2008)

135. Second-order nonlinear differential equations with infinite set of periodic solutions. Nonlinear Oscil. 11(4), 521-526 (2008)

136. The Neumann problem for the second order nonlinear ordinary differential equations at resonance. Funct. Differ. Equ. 16(2), 353-371 (2009)

137. Bounded and vanishing at infinity solutions of nonlinear differential systems. Georgian Math. J. 16(4), 711-724 (2009)

138. On boundary value problems with conditions at infinity for nonlinear differential systems. Nonlinear Anal. 71, 1503-1512 (2009)

139. Periodic solutions of nonautonomous ordinary differential equations. Monatshefte Math. 159(3), 235-252 (2010) (together with Lomtatidze, A)

140. Optimal conditions of solvability and unsolvability of nonlocal problems for essentially nonlinear differential systems. Commun. Math. Anal. 8(3), 92-101 (2010)

141. Optimal conditions of solvability of nonlocal problems for second-order ordinary differential equations. Nonlinear Anal. 74(3), 757-767 (2011) (together with Kiguradze, T)

142. Conditions for the well-posedness of nonlocal problems for second-order linear differential equations. Differ. Uravn 47(10), 1400-1411 (2011) (in Russian) (together with Kiguradze, T)

143. Conditions for well-posedness of nonlocal problems for higher order linear differential equations with singularities. Georgian Math. J. 18(4), 735-760 (2011) (together with Kiguradze, T)

144. Solvability conditions for non-local boundary value problems for two-dimensional half-linear differential systems. Nonlinear Anal. 74, 6537-6552 (2011) (together with Šremr, J)

145. The Dirichlet and focal boundary value problems for higher order quasi-half linear singular differential equations. Mem. Differ. Equ. Math. Phys. 54, 126-133 (2011)

146. Some multi-point boundary value problems for second order singular differential equations. Mem. Differ. Equ. Math Phys. 56, 133-141 (2012) (together with Lomtatidze, A, Partsvania, N)

147. On nonlocal problems with nonlinear boundary conditions for singular ordinary differential equations. Mem. Differ. Equ. Math. Phys. 59, 113-119 (2013)

148. The Cauchy problem for singular in phase variables nonlinear ordinary differential equations. Georgian Math. J. 20(4), 707-720 (2013)

149. A priori estimates of solutions of nonlinear boundary value problems for singular in a phase variable second order differential inequalities. Georgian Math. J. 21(2), 211-224 (2014)

150. Nonlinear nonlocal problems for second order singular in a phase variable differential equations. Differ. Uravn. 50 (2014, accepted) (in Russian)

151. Positive solutions of periodic type boundary value problems for first order singular functional differential equations. Georgian Math. J. 21(3), 303-311 (2014) (together with Sokhadze, Z)

doi:10.1186/s13661-014-0228-x

Cite this article as: Rachůnková et al.: A tribute to Ivan Kiguradze. Boundary Value Problems 2014 2014:228. 